\title{
Logística Reversa nas Indústrias de Plásticos de Teresina-PI: Um Estudo de Viabilidade
}

\author{
Elaine A. da Silva, José M. Moita Neto \\ Programa de Pós-Graduação em Desenvolvimento e Meio Ambiente, UFPI
}

\begin{abstract}
Resumo: O aumento do consumo de plásticos tem como consequência direta a geração de resíduos pós-consumo desses materiais, demandando uma atenção especial para o setor. Pelo princípio do poluidor-pagador, os fabricantes têm responsabilidade sobre o gerenciamento dos materiais que produzem. O objetivo deste trabalho é analisar a viabilidade de implantação da logística reversa nas indústrias do setor de plásticos da cidade de Teresina, capital do Piauí. Realizaram-se visitas in loco em nove indústrias que produzem artefatos de plásticos. Foram feitas entrevistas com os administradores, a fim de conhecer o processo produtivo, as matérias-primas utilizadas e a sua origem, além da análise da possibilidade da reinserção dos resíduos pós-consumo na cadeia produtiva e/ou de negócios. Constatou-se que a aplicação da logística reversa é uma realidade distante para o setor. A inexistência de um programa consolidado de coleta seletiva e a falta de uma legislação efetiva possibilita que as indústrias optem ou não por estabelecer a logística reversa em seus processos. O estabelecimento futuro da logística reversa no setor de plásticos de Teresina-PI depende do incremento nas atividades de pesquisa e inovação tecnológica e da criação de um mercado para produtos reciclados.
\end{abstract}

Palavras-chave: Logística reversa, reciclagem, plásticos.

\section{Reverse Logistics in the Manufacturing of Plastics in Teresina-PI: A Feasibility Study}

\begin{abstract}
The increased consumption of plastics brings the generation of post-consumer waste, which requires special attention from this industrial sector. According to the principle of polluter pays, manufacturers have responsibility for managing the materials they produce. This study examines the feasibility of introducing reverse logistics in the plastics industry in the city of Teresina, capital of Piauí, Brazil. Nine industries that produce plastics were visited. Directors of such industries were interviewed to talk about the production process, raw materials used and their origin, and were questioned about the possibility of recycling post-consumer waste to be reused in the production chain and/or business. We found that the application of reverse logistics is a distant reality for the sector. The lack of a consolidated program of selective collection and lack of effective legislation allow industries not to choose to implement reverse logistics processes. The future establishment of reverse logistics in the sector of plastics and rubber in Teresina-PI depends on the increase in research activities and technological innovation, in addition to the creation of a market for recycled products.
\end{abstract}

Keywords: Reverse logistics, recycling, plastics.

\section{Introdução}

A cadeia produtiva petroquímica e de transformação de plásticos é constituída por três gerações: os produtores de primeira geração (craqueadores) que fracionam a nafta (subproduto do processo de refino de petróleo) ou o gás natural, transformando-os em petroquímicos básicos, como as olefinas e os aromáticos. As unidades de segunda geração produzem resinas termoplásticas como os polietilenos (linear, alta e baixa densidade) e o polipropileno, além de intermediários, resultantes do processamento de produtos primários, como o estireno, o acetato de vinila, entre outros ${ }^{[1]}$.

Segundo a Associação Brasileira da Indústria do Plástico (ABIPLAST) $)^{[2]}$, o consumo aparente de artefatos plásticos, o qual é obtido a partir do total produzido acrescido do importado, menos o total exportado, atingiu em 2008 a expressiva quantidade de 5.298 mil toneladas. Comparativamente ao ano 2000, o consumo de transformados plásticos cresceu de forma acumulada na razão de $33 \%$.

De acordo com a Agência Brasileira de Desenvolvimento Industrial $(\mathrm{ABDI})^{[1]}$, os tipos de polímeros mais consumidos, atualmente, são os polietilenos, polipropilenos, poli (cloreto de vinila), poliestirenos, poliésteres e poliuretanos. Grande parte dos plásticos transformados pela indústria são destinados ao setor de embalagens em geral, ou seja, produtos de baixo tempo de ciclo de vida e, portanto, de grande descartabilidade, configurando uma das principais preocupações ambientais da sociedade moderna.

$\mathrm{Na}$ visão dos produtores da segunda geração (produção de resinas termoplásticas), em todo o seu ciclo de vida, o plástico é capaz de gerar milhares de empregos, contribuir para a manutenção da saúde pública, evitando doenças e infecções, garantir a conservação e a preservação de alimentos e movimentando grande parcela da economia de todas as nações ${ }^{[3]}$.

Para fins de reaproveitamento, é necessário considerar a classificação dos plásticos, de acordo com o seu comportamento à moldagem em: termoplásticos e termoestáveis. Os primeiros caracterizam-se por poderem ser endurecidos ou amolecidos reversivelmente. Os termoestáveis (termofixos, termoduros) apresentam melhor resistência à temperatura, estabilidade dimensional, resistência química e propriedades elétricas superiores às dos termoplásticos. Os processos de moldagem dos termoestáveis são mais caros, especialmente por não apresentarem um alto nível de automatização.

Outra medida importante é a identificação do tipo de plástico. A NBR 13230/2008, da Associação Brasileira de Normas Técnicas (ABNT), estabelece símbolos para identificação das resinas termoplásticas ${ }^{[4]}$, utilizadas na fabricação de embalagens e acondicionamento de plásticos, visando a auxiliar na separação e posterior reciclagem dos materiais, de acordo com a composição.

Autor para correspondência: Elaine A. da Silva, Programa de Pós-Graduação em Desenvolvimento e Meio Ambiente, Universidade Federal do Piauí, Av. Universitária, 1310, Campus Universitário Ministro Petrônio Portela, Ininga, CEP 64049-550, Teresina, PI, Brasil. E-mail: elaine@ufpi.edu.br 
Como afirma Coltro et al. ${ }^{[5]}$, a presença do símbolo de identificação da resina na embalagem não garante ou implica que a mesma é adequada para reciclagem, mas certamente facilita a separação ou, no mínimo, permite que esta não venha a comprometer a qualidade de outras cadeias de reciclagem.

No trabalho intitulado "Reciclagem de Materiais Plásticos: A Importância da Identificação Correta", Coltro et al. ${ }^{[5]}$ concluíram que ainda existe falta de informação no mercado brasileiro sobre o tipo de resina da embalagem plástica, bem como sobre o símbolo correto de identificação do material, sendo que ambos os fatores prejudicam a cadeia de reciclagem do plástico.

A constatação do crescente consumo de produtos de plásticos e, por isso, a geração de resíduos pós-consumo desses materiais, faz com que seja dada uma atenção especial para o setor. Dessa forma, neste trabalho, identificamos as principais indústrias de plásticos da cidade de Teresina, capital do estado do Piauí, a fim conhecer aspectos que direcionem o retorno dos produtos pós-consumo para essas indústrias.

\section{Novos Cenários}

Escassez de matéria-prima, problemas causados pelo descarte inadequado dos resíduos sólidos e uma crescente pressão da sociedade, tem motivado o aprimoramento da legislação ambiental brasileira, para considerar o reaproveitamento dos materiais descartados pelos consumidores finais.

O princípio do poluidor-pagador, na Política Nacional do Meio Ambiente (Lei Federal no 6.938/1981), estabelece que, quem produz deve responsabilizar-se pelo destino dos produtos gerados, de forma a reduzir os impactos ambientais que eles causam. A maneira mais favorável para que esse processo tenha chances de sucesso é o reaproveitamento do material pós-consumo na cadeia produtiva e/ ou de negócios.

Piazza, et al. ${ }^{[6]}$ consideram que estamos diante de uma nova tendência, onde as empresas, para permanecerem no mercado, precisarão atualizar-se na busca de novas alternativas para a redução nos impactos ambientais de seus processos e produtos. Assim, devem considerar desde os insumos materiais e energéticos da produção até o reaproveitamento e a disposição final dos resíduos e dos próprios produtos.

O documento "Indústria Sustentável no Brasil - Agenda 21: Cenários e Perspectivas", da Confederação Nacional das Indústrias (CNI), aponta que estratégias de promoção da qualidade e da competitividade, ao longo dos anos 90, cumpriram um papel importante no processo de ajuste das indústrias brasileiras ao novo ambiente, induzido pela abertura econômica, contribuindo para a melhoria da eficiência nas empresas ${ }^{[7]}$.

No entanto, o maior motivador para a incorporação da dinâmica ambiental nas indústrias é, sem dúvida, uma legislação ambiental eficiente. A Política Nacional dos Resíduos Sólidos (PNRS) instituída pela Lei Federal $n^{\circ} 12.305$, de 2 agosto de 2010, traz responsabilidades não só para os fabricantes e os importadores dos produtos, mas, também, para os consumidores e os revendedores, comerciantes e distribuidores, significa que todos têm uma responsabilidade compartilhada sobre os produtos pós-consumo ${ }^{[8]}$.

Aspectos contrastantes, como a degradação lenta e volumetria elevada dos plásticos, que compromete a vida útil dos aterros, a existência de várias propriedades diferentes entre si, dificultando a identificação e seleção dos resíduos (principalmente, dos plásticos) e o elevado potencial econômico para reutilização e reciclagem, fundamentam a importância do estudo da viabilidade do retorno desses materiais à indústria para o seu reaproveitamento.

\section{Logística Reversa}

A logística, área tradicional da administração e etapa essencial de muitas atividades industriais e comerciais, é responsável pelo percurso do produto desde a aquisição da matéria-prima até o ponto de consumo final. Dessa forma, a atividade logística compreende o estabelecimento das relações entre os fabricantes e os revendedores, além da entrega de bens aos consumidores. Portanto, com a finalidade de atender as exigências do consumidor.

A boa administração logística interpreta cada atividade como contribuinte do processo de agregação de valor. Assim, quando pouco valor pode ser agregado, torna-se questionável a própria existência dessa atividade. Contudo, agrega-se valor quando os consumidores estão dispostos a pagar, por um produto ou serviço, mais que o custo de colocá-lo ao alcance deles ${ }^{[9]}$.

Rogers e Tibben-Lembke ${ }^{[10]}$ fizeram uma adaptação do conceito de logística reversa, a partir da definição de logística do Council of Logistics Management, conceituando-a como o processo de planejamento, implementação e controle da eficiência do custo efetivo do fluxo de matérias-primas, estoques em processo, produtos acabados e as informações relacionadas com o ponto de consumo ao ponto de origem, a fim de recapturar valor ou destinar adequadamente.

Uma definição mais atual de Logística Reversa encontra abrigo na Lei Federal n ${ }^{\circ}$ 12.305/2010, que a define como:

[...] instrumento de desenvolvimento econômico e social caracterizado por um conjunto de ações, procedimentos e meios destinados a viabilizar a coleta e a restituição dos resíduos sólidos ao setor empresarial, para reaproveitamento, em seu ciclo ou em outros ciclos produtivos, ou outra destinação final ambientalmente adequada ${ }^{[8]}$.

Motivada pela proposição de um melhor destino aos materiais pós-consumo, a logística reversa tem como finalidade última atender as novas exigências ambientalmente corretas da sociedade.

A logística reversa pode ser dividida em duas áreas de atuação: logística reversa de pós-venda e logística reversa de pós-consumo. A primeira pode ser entendida como a área da logística reversa que trata do planejamento, do controle e da destinação dos bens sem uso ou com pouco uso, que retornam à cadeia de distribuição por diversos motivos, como: devoluções por problemas de garantia, avarias durante o transporte, prazo de validade expirado, entre outros. A logística reversa de pós-consumo pode ser entendida como a área da logística reversa que trata dos bens no final de sua vida útil, dos bens usados com possibilidade de reutilização (embalagens) e os resíduos industriais (que devem retornar às indústrias para descarte final ambientalmente correto).

Mutha e Pokharel ${ }^{[11]}$ consideram que a logística reversa tem recebido apreciável atenção, no mundo, devido aos potenciais de valorização dos produtos utilizados; além de, legislações e diretrizes, da consciência do consumidor e da responsabilidade social com o meio ambiente.

No ordenamento jurídico brasileiro, a obrigatoriedade pelo retorno dos materiais, já é realidade para o caso das pilhas e baterias (Resolução CONAMA no 257/99) $^{[12]}$, dos pneumáticos (Resolução CONAMA $n^{\circ}$ 416/09) $)^{[13]}$ e das embalagens de agrotóxicos (Resolução CONAMA n $\left.{ }^{\circ} 334 / 03\right)^{[14]}$.

Desse modo, o objetivo deste trabalho é analisar a viabilidade de implantação da logística reversa nas indústrias do setor de plásticos de Teresina. Portanto, analisar a possibilidade da reinserção dos resíduos pós-consumo na cadeia produtiva e/ou de negócios. 


\section{Metodologia}

Teresina tem uma população superior a 800.000 habitantes e é o centro de uma região metropolitana, que supera um milhão de habitantes. Nesta cidade, foram visitadas nove indústrias de plásticos. Na Tabela 1, estão indicados o bairro em que estão localizadas, a quantidade de funcionários e a principal matériaprima processada.

As indústrias de plásticos pesquisadas correspondem à terceira geração petroquímica, que engloba o segmento dos transformadores plásticos que, através de processos industriais variados, utilizando diferentes tecnologias, como extrusão, sopro, injeção, termoformagem, compressão, imersão, transformam os produtos da segunda geração petroquímica em produtos a serem consumidos e utilizados diretamente pela população.

Foram agendadas visitas e entrevistas semi-estruturadas com os dirigentes das indústrias. As entrevistas, que combinavam perguntas abertas e fechadas, balizadas por perguntas norteadoras (conjunto de questões previamente definidas), foram elaboradas a partir das especificidades do setor, tais como: a possibilidade de reprocessamento do plástico pós-consumo, a existência de iniciativas na área ambiental e a possibilidade de produção do plástico biodegradável, conforme Apêndice 1 .

Em cada visita foram anotadas, ainda, as matérias-primas utilizadas e a sua origem, as etapas do processo produtivo, os tipos de produtos que industrializavam, os tipos e volumes de embalagens utilizadas para o acondicionamento dos produtos, além dos resíduos gerados e do gerenciamento adotado por estas indústrias para os mesmos. Também, observou-se aspectos gerais de segurança, qualidade e meio ambiente. As visitas foram realizadas de março a maio de 2010 .

Os dados obtidos através das visitas às instalações das indústrias e das entrevistas foram analisados, conforme as especificidades do setor. Além disso, discutiu-se, neste trabalho, maneiras de reinserir o resíduo pós-consumo da indústria de plásticos de Teresina, na sua cadeia produtiva e/ou de negócios.

\section{Resultados}

A descrição das atividades das indústrias visitadas foi feita agrupando-as conforme o principal tipo de resina que utilizam:

\section{a) Polietileno (PE)}

Os produtos oferecidos são embalagens (sacos e sacolas) flexíveis que podem ser lisas, impressas ou com tratamento para serigrafia. Além do Polietileno de Baixa Densidade (PEBD) e do Polietileno de Alta Densidade (PEAD), estas indústrias utilizam Polipropileno (PP), solventes, pigmentos e aditivos. Os principais fornecedores são a Braskem e a Quattor (segunda geração na cadeia produtiva dos plásticos). Os seus clientes são os supermercados, clínicas, hospitais, empresas de confecções, distribuidores, entre outros.
Nessas indústrias, todas as aparas e as embalagens que não estiverem dentro das conformidades (apresentarem alguma falha de produção) são reaproveitadas. As embalagens que não têm condições de retornar ao processo são vendidas para outras indústrias, que produzem grãos de resina reciclada, sacos e sacolas a partir do Polietileno, e que têm suporte para realizar a limpeza desse material.

As etapas do processo produtivo do grão de resina (granulado), a partir de resíduos plásticos comprados de outras indústrias, dos sucateiros ou de associações que trabalham com a coleta de material para reciclagem (plástico pós-consumo) são as seguintes: primeiramente, é feita a triagem dos resíduos, onde são selecionados os materiais adequados para o processo de reaproveitamento. Depois disso, estes materiais são colocados em uma esteira, onde é feita a detecção e a retirada de metais. Após a esteira, o plástico é triturado e lavado no moinho, seguindo para o tanque com agitador, onde o material de interesse é selecionado por densidade. Posteriormente, o plástico é encaminhado aos secadores e, novamente, para outro moinho, a fim de ser cortado em partes ainda menores. Em seguida, o plástico e o pigmento são colocados na extrusora. Ao final deste processo tem-se a matéria-prima denominada de resina reciclada. A produção diária de resinas recicladas, em Teresina, fica entre 2500 e $3000 \mathrm{~kg}$. As resinas recicladas são utilizadas para a fabricação das sacolas recicladas.

Outra indústria que utiliza o Polietileno como matéria-prima principal produz garrafas plásticas de 300 e de $500 \mathrm{~mL}$. Nesta indústria, são produzidas, diariamente, 10.000 garrafas que utilizam cerca de $2.000 \mathrm{~kg}$ de PEAD e PEBD por semana. As garrafas são comercializadas para as indústrias envasadoras de água de côco, sucos, iogurtes, mel e temperos do Piauí e do Maranhão. O seu valor varia entre $\mathrm{R} \$ 0,19$ e $\mathrm{R} \$ 0,36$. Todas as aparas (sobras geradas pelo processo) dessa indústria são reaproveitadas no processo produtivo. Para o reprocessamento, as aparas são trituradas e misturas à matéria-prima virgem na proporção de 1:1.

No caso da indústria alimentícia, deve-se ter o cuidado especial com a reutilização das embalagens na própria indústria. $\mathrm{O}$ mais recomendado é o uso das mesmas em outro setor industrial. A utilização, os limites de materiais plásticos e os eventuais aditivos que compõe as embalagens de alimentos são disciplinados pela Agência Nacional de Vigilância Sanitária (ANVISA). Assim, a alternativa apontada pelo entrevistado é o reprocessamento desse material para a produção de garrafas para detergentes e desinfetantes. No entanto, o mesmo não tem interesse em realizar essa atividade, por considerar que esses produtos não tem mercado no Piauí e no Maranhão.

Apenas uma das indústrias visitadas produz embalagens oxibiodegradáveis. $\mathrm{O}$ aditivo usado na produção das embalagens desse tipo leva à decomposição das ligações carbono-carbono no plástico, diminuindo o peso molecular, causando uma perda de resistência mecânica e facilitando o ataque químico.

Tabela 1. Indústrias do setor de plásticos visitadas em Teresina

\begin{tabular}{ccccc}
\hline Indústria & Bairro & Funcionários & Principal matéria-prima & Sigla \\
\hline A & Pedra Mole & 22 & Poli(cloreto de vinila) & PVC \\
B & Distrito Industrial & 50 & Poli(etileno-co-acetato de vinila) & EVA \\
C & Memorare & 102 & Poliestireno & PS \\
D & Distrito Industrial & 250 & Polietileno/polipropileno & PE/PP \\
E & Distrito Industrial & 38 & Polietileno & PE \\
F & Santo Antônio & Polietileno & PE \\
G & Areias & 30 & Polietileno & PE \\
H & Aeroporto & 22 & Polietileno & PE \\
I & Angelim & 15 & Polipropileno & PP \\
\hline
\end{tabular}


A produção das embalagens oxi-biodegradáveis tende a aumentar por conta da obrigatoriedade estabelecida na Lei Municipal $n^{\circ} 3.874 / 09$, de estabelecimentos comerciais, farmácias, lanchonetes, panificadoras e afins, utilizarem para acondicionamento de produtos e mercadorias em geral, sacolas biodegradáveis ou oxibiodegradáveis, ou de papel ou de tecidos retornáveis ${ }^{[15]}$.

\section{b) Polipropileno (PP)}

Na produção de bacias e baldes, todas as aparas são reprocessadas. Dessa forma, não há perdas de matéria-prima durante e nem após o processo produtivo; já que, se algum dos artefatos não estiver em boas condições para a comercialização, é triturado e reencaminhado para o processo produtivo.

\section{c) Poli (cloreto de vinila) (PVC)}

$\mathrm{Na}$ indústria pesquisada, são produzidos 2000 tubos de PVC por dia para sistema de abastecimento de água, sistema de esgotamento sanitário e eletroduto. As matérias-primas utilizadas são o PVC, estearato de cálcio, carbonato de cálcio, dióxido de titânio, estabilizante e os pigmentos. As casas de construção e as construtoras estão entre os principais clientes dessa indústria.

Não há geração de resíduos industriais durante o processo produtivo, as aparas são reprocessadas e os tubos que não estão em conformidade também.

O consumo dos tubos de PVC tem aumentado nos últimos anos. Uma das causas apontadas é o incentivo do governo federal em infra-estrutura, particularmente, em saneamento e energia.

Na opinião do entrevistado, se Teresina tivesse um programa consolidado de coleta seletiva, e, além disso, os plásticos fossem separados de acordo com o tipo, a indústria estaria preparada para receber o PVC. Por causa disso, ainda é mais barato comprar o PVC do que contratar pessoas para fazer a seleção desse material.

\section{d) Poliestireno (PS)}

A indústria visitada produz, aproximadamente, 40.000 caixas de copos e pratos descartáveis por mês. Esse valor é ainda maior nos períodos de carnaval e das festas de fim de ano. Para isso, os funcionários trabalham, alternadamente, durante os três turnos.

As matérias-primas, compradas de grandes indústrias localizadas no estado de São Paulo, como a Basf, Dow e MaxPoli, são o poliestireno e os pigmentos. Utilizam $160 \mathrm{t}$ de poliestireno e três toneladas de pigmentos por mês.

Para o entrevistado, gerente de produção e responsável pela área logística da indústria, o consumo de descartáveis tem aumentado nos últimos anos. Esse aumento tem se mostrado representativo, sobretudo, nas clínicas.

Cerca de $30 \%$ do filme se transforma em aparas que são reaproveitadas no processo produtivo. A quantidade de resíduos industriais encaminhados ao aterro municipal é pequena, incluindo os contaminados com óleo e graxa das máquinas. O envio deste material para o aterro não é um procedimento correto, pois o mesmo não fornece tratamento adequado aos resíduos industriais.

$\mathrm{Se}$ as aparas geradas durante o processo produtivo podem ser reprocessadas, o material descartável pós-consumo não é diferente. Entretanto, só é possível que isso aconteça em indústrias que tenham outra finalidade, que não a produção voltada para a indústria alimentícia, como é a dos copos e pratos descartáveis. Dessa forma, a alternativa apontada pelo entrevistado é a produção de baldes e mangueiras; o que, atualmente, não é objetivo da indústria.

\section{e) Poli (etileno-co-acetato de vinila) (EVA)}

A única indústria que faz o processamento e o reprocessamento da borracha, no Piauí, produz uma média de quinhentos pares de sandálias por dia. Além disso, produzem outros componentes para calçados, pisos partilhados de borracha, tatames, placas de E.V.A e a microdura (utilizada no solado do calçado), que é uma invenção patenteada da própria indústria.

As matérias-primas utilizadas são o pó do pneu, os retalhos de borracha, plástico e os produtos químicos (Enxofre, TMTD Thiuram, Ácido Esteárito - Estearina, Peróxido, MTb, Expansor AZ, Carbonato, Caulim, Polietileno, Óleo e E.V.A). Tanto o pó do pneu quanto os retalhos de borracha são tratados antes da utilização na indústria. Não foi informado o tipo de tratamento utilizado na indústria.

Das matérias-primas utilizadas, o plástico e os produtos químicos são comprados. Os outros componentes são doados pelas indústrias de reforma de pneus do estado ("renovadoras de pneus") e por outras indústrias que produzem calçados. A indústria assina um documento que comprova a destinação dos resíduos doados pelas empresas geradoras. $\mathrm{O}$ administrador comentou que as empresas geradoras de resíduos têm interesse em fazer a doação devido ao mercado de créditos de carbono, embora ele não saiba como isto ocorre na prática.

Os principais clientes são as empresas que vendem artigos de couro e fábricas de calçados (mantas de borracha), supermercados (sandálias), livrarias (folhas de E.V.A), academias (tatames) e empresas de eventos (sandálias personalizadas, viseiras, chapéus). Os seus produtos são vendidos para todos os estados do Nordeste, além de Brasília e São Paulo.

Todos os resíduos gerados durante o processo produtivo são reprocessados. De acordo com o administrador, o reprocessamento acontece com $25 \%$ da produção, que corresponde às sobras das máquinas e as aparas geradas durante o corte da borracha.

O combustível utilizado para alimentar as máquinas da indústria é a lenha. A Prefeitura de Teresina destina para a indústria os resíduos de poda. Além disso, a indústria realiza a coleta desse material, desde que seja apresentada ao seu proprietário a licença da Prefeitura para a realização do corte ou poda da árvore.

De acordo com o administrador, toda a sua produção pode voltar à cadeia produtiva, mesmo depois da sua utilização pelos consumidores. Assim, se Teresina tivesse um programa consolidado de coleta seletiva, seria mais fácil para a indústria realizar esse trabalho. Isso porque, não compensa para a mesma fazer um investimento para que aconteça a logística reversa.

\section{Discussão}

Os sinais de implementação de melhorias contínuas nas indústrias, no que se refere às questões ambientais, e que podem ser considerados indicativos de sensibilidade à implementação futura da logística reversa são os seguintes: 1) métodos que reduzem o desperdício, considerando o reaproveitamento de resíduos do processo produtivo; 2) métodos que melhorem o uso de insumos, com o aumento da eficiência energética e a diminuição do consumo de água; e 3) modelos de gestão voltados para a qualidade do produto e da segurança do trabalho dos funcionários.

Em geral, as indústrias visitadas apresentam uma boa estrutura física, além de organizar a disposição das máquinas e dos funcionários de acordo com as distintas etapas do processo produtivo. Durante as visitas, constatou-se a utilização dos equipamentos de proteção individual - EPIs pelos funcionários (capacetes, máscaras, protetor auricular, luvas e botas).

Duas indústrias, a que utiliza o poliestireno e o PVC como matéria-prima principal, são as mais preocupadas com a qualidade dos seus produtos. Isso porque, eles devem estar em conformidade com as normatizações da Associação Brasileira de Normas Técnicas (ABNT). 


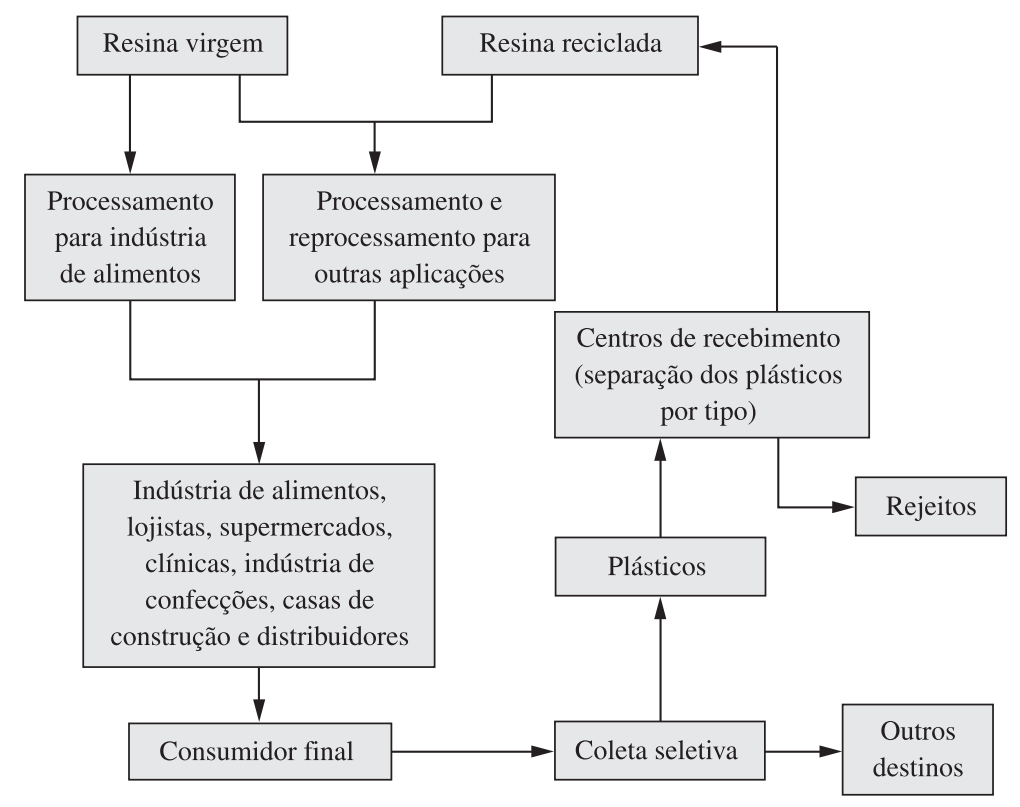

Figura 1. Fluxograma direto e inverso (proposta) das indústrias de plásticos de Teresina.

Por outro lado, nenhuma das indústrias visitadas apresentou um modelo de compromisso sócio-ambiental que as destaque. Quando o fazem, é para a economia de matéria-prima, como no caso do reaproveitamento das aparas, de modo a minimizar perdas do processo (gerando poucos resíduos) ou para a economia de energia (mais ligada às questões financeiras do que à preocupação com o meio ambiente).

Há uma resistência dos administradores das indústrias visitadas na utilização do aditivo para a produção das embalagens oxibiodegradáveis, por três motivos: o aumento nos custos da produção da embalagem, menor tempo que essa poderá ficar estocada na indústria (podendo haver prejuízos) e por considerarem que a efetividade da lei, em nada contribui para a melhoria ambiental; já que, a função do aditivo é apenas dividir o plástico em partículas menores (cominuição), pois o mesmo não é absorvido pela natureza, apenas vira pó.

Das indústrias visitadas, três trabalham com material pósconsumo. Esses materiais são comprados ou recebidos por meio de doação para serem utilizados como matéria-prima na fabricação dos seus produtos. As indústrias procuram adquirir a matériaprima desejada previamente segregada, optando por materiais que apresentem uma relativa homogeneidade. Esses casos demonstram a possibilidade existente de reutilização dos materiais pós-consumo no local de origem; tendo em vista que, os resíduos pós-consumo adquiridos correspondem às matérias-primas principais dessas indústrias.

Entretanto, as indústrias que compram o plástico pós-consumo para a produção de resinas, com a finalidade de colocar no mercado as sacolas recicladas, utilizam uma grande quantidade de água para realizar a limpeza desse material. No momento da visita, nenhuma delas apresentou um funcionário responsável pelo tratamento do efluente, não sabendo, por isso, explicar como o mesmo acontece, e nem a quantidade de água utilizada. Também, no processo de reciclagem, há um gasto extra de energia (moinho, secadores, esteiras, etc.), portanto, é necessária uma avaliação mais criteriosa da relação custo/benefício desta atividade para o meio ambiente. A logística reversa (coleta, triagem, transporte e processamento) só será factível se os custos de produção do reciclado for compatível com o do granulado virgem.
Na Figura 1 é apresentado um fluxograma da logística direta e reversa de possível aplicação nas indústrias de plásticos de Teresina. O fluxo logístico ideal consiste na entrada de matéria-prima da indústria de plásticos sendo composto por resinas virgens e resinas recicladas. As resinas virgens obtidas diretamente das unidades de segunda geração e as resinas recicladas obtidas no comércio local ou dentro da própria indústria. Os artefatos plásticos para o setor de alimentos e bebidas sendo feitos exclusivamente de resina virgem. Todos os artefatos pós-consumo são direcionados para a reciclagem sendo inicialmente separados de outros materiais através de coleta seletiva e, posteriormente, separado por tipos de polímeros dentro das unidades recicladoras. Para isso, é importante a implementação de um programa de coleta seletiva pelo poder público com apoio da população e a criação de centros de recebimento e reciclagem com apoio da indústria.

\section{Conclusão}

A falta de uma legislação que obrigue ou, pelo menos, incentive a volta desses materiais às indústrias de origem, admite que as mesmas possam escolher se querem ou não realizar o processo. Por não se considerarem responsáveis por esse material pós-consumo, os administradores das indústrias visitadas optam por comprar matéria-prima virgem ou matéria-prima previamente segregada; já que, é mais rentável para os mesmos, do que contratar pessoas para fazer a seleção do material.

Das indústrias visitadas, cinco poderiam reutilizar o seu material pós-consumo no próprio processo produtivo, diminuindo os seus custos com a compra da matéria-prima. As demais, se recebessem o material de volta, teriam que procurar um destino ambientalmente adequado para o mesmo; pois, os seus produtos são voltados para a indústria alimentícia.

Outra dificuldade de reaproveitamento, pelas indústrias visitadas, do material pós-consumo reside, principalmente, no fato de que, inexiste um programa consolidado de coleta seletiva em Teresina. Além da coleta seletiva, para o estabelecimento da logística reversa no setor estudado, é importante que as indústrias assumam a responsabilidade de identificar seus produtos com os códigos estabelecidos na ABNT, o que facilitaria o seu retorno. 
O efetivo estabelecimento da logística reversa depende de dois fatores: incremento das atividades de pesquisa e inovação tecnológica e a criação de um mercado para produtos reciclados.

\section{Referências Bibliográficas}

1. Agência Brasileira de Desenvolvimento Industrial - ABDI. "Caracterização da cadeia petroquímica e da transformação de plásticos", Copacabana Consultoria e Treinamento, São Paulo (2009).

2. Associação Brasileira da Indústria do Plástico - ABIPLAST. - "Perfil 2008: Indústria Brasileira de Transformação de Material Plástico", ABIPLAST, São Paulo (2008).

3. QUATTOR - "Embaixadores dos plásticos" (2010). Disponível em: $<$ http://www.quattor.com.br/quattorweb/pt/eplastico.aspx>. Acesso em: 29 nov. 2010.

4. Associação Brasileira de Norma Técnica - ABNT. - "NBR 13230: simbologia indicativa de reciclabilidade e identificação de materiais plásticos". Rio de Janeiro, 8p. (2006).

5. Coltro, L. et al. - Polímeros, 18, p.119 (2008).

6. Piazza, C. A. D. et al. "Logística reversa e suas contribuições ambientais", in: Fórum Ambiental da Alta Paulista, v.III (2007).

7. Confederação Nacional da Indústria - CNI. - "Indústria Sustentável no Brasil - Agenda 21: cenários e perspectivas", CNI/DIREX, Brasília (2002).

8. BRASIL. - "Lei n 12.305 , de 02 de agosto de 2010. Institui a Política Nacional de Resíduos Sólidos" (2010). Disponível em: <http://www. planalto.gov.br/ccivil_03/_ato2007-2010/2010/lei/112305.htm>. Acesso em: 29 nov. 2010.

9. Ballou, R. H. "Gerenciamento da cadeia de suprimentos: logística empresarial”, Bookman, Porto Alegre (2006).
10. Rogers, D. \& Tibben-lembke, R. - "Going Backwards: reverse logistics trends and practices", University of Nevada, Reno Center for Logistics Management (1998).

11. Mutha, A. \& Pokharel, S. - Comp. Industrial Eng., 56, p.334 (2009).

12. Brasil. Conselho Nacional do Meio Ambiente - CONAMA. "Resolução n ${ }^{\circ} 257$, de 30 de junho de 1999. Dispõe sobre o descarte e o gerenciamento ambientalmente adequado de pilhas e baterias usadas", Diário Oficial da União, Brasília, 22 jul. (1999).

13. Brasil. Conselho Nacional do Meio Ambiente - CONAMA. "Resolução n ${ }^{\circ} 416$, de 30 setembro de 2009. Dispõe sobre a prevenção à degradação ambiental causada por pneus inservíveis e sua destinação ambientalmente adequada", Diário Oficial da União, Brasília, 1 out. (2009).

14. Brasil. Conselho Nacional do Meio Ambiente - CONAMA. "Resolução n ${ }^{\circ} 334$, de 03 abril de 2003. Dispõe sobre os procedimentos de licenciamento ambiental de estabelecimentos destinados ao recebimento de embalagens vazias de agrotóxicos", Diário Oficial da União, Brasília, 19 maio (2003).

15. Teresina. "Lei $\mathrm{n}^{\mathrm{o}} 3.874$, de 09 de junho de 2009. Dispõe sobre a obrigatoriedade de estabelecimentos comerciais, farmácias, lanchonetes, panificadoras e afins utilizarem para o acondicionamento de produtos e mercadorias em geral, sacolas biodegradáveis ou oxibiodegradáveis, ou de papel ou de tecidos retornáveis, na forma em que especifica", Diário Oficial do Município, Teresina. Disponível em: <http://www.teresina.pi.gov.br/dom/doc_diario/DOM1281-119062009.pdf>. Acesso em: 29 nov. (2010).

Enviado: 09/06/10

Reenviado: 29/11/10

Aceito: $07 / 12 / 10$

DOI: 10.1590/S0104-14282011005000041

Apêndice 1. Perguntas norteadoras para as indústrias de plásticos de Teresina-PI.

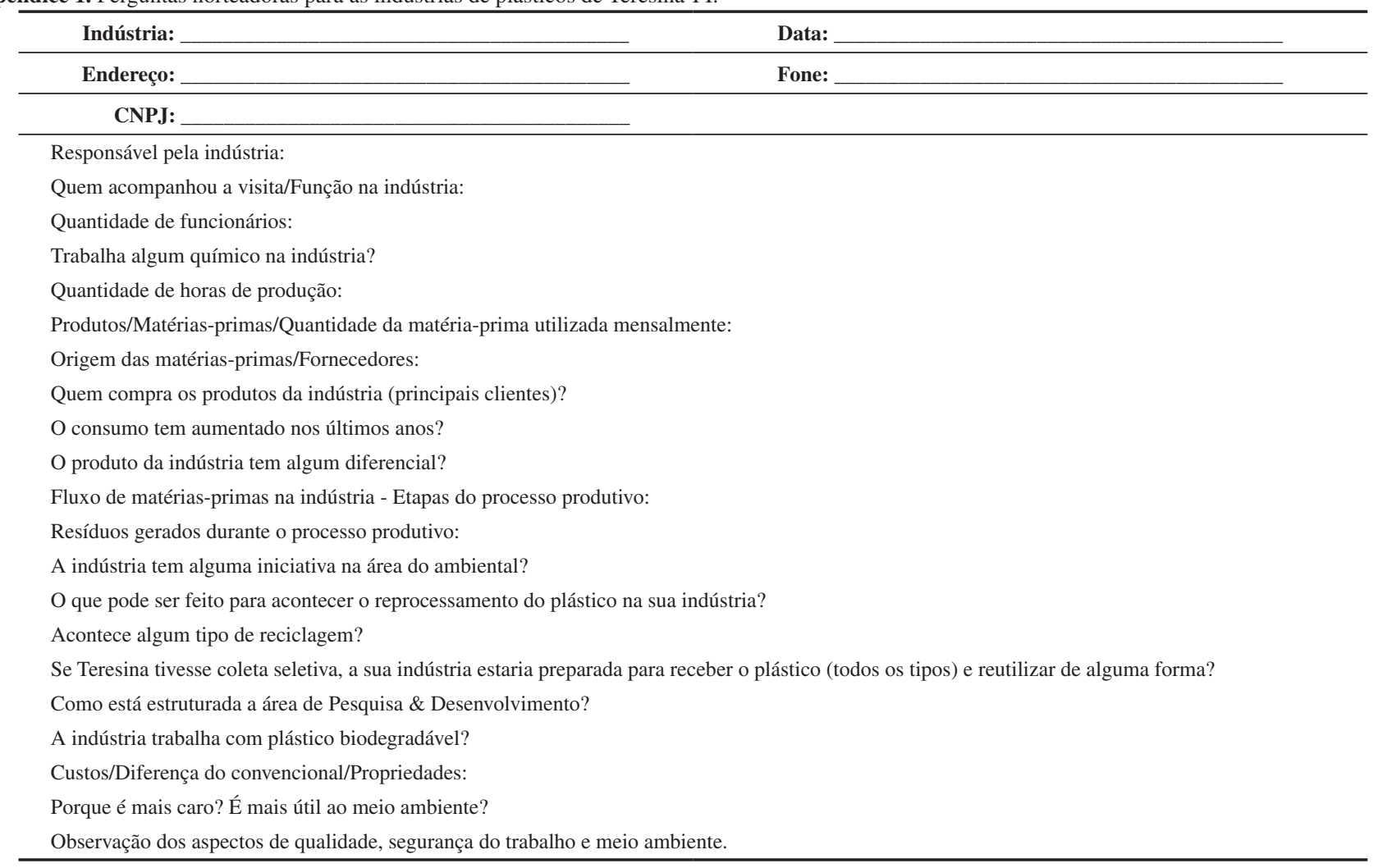

